\title{
Construction of River Water Pollution Monitoring Information System Based on Contamination Detection Technologies
}

\author{
Lakshya Sharma
}

\begin{abstract}
This paper provides with a common ground to discuss various aspects affecting the pollution of the river Yamuna. The paper analyses data from different studies to interpret the possible causes and recommendations. The paper deeply explains relatively newer and older methods for the detection of water pollution like laboratory oil analysis, chromatography, etc.
\end{abstract}

Keywords: Pollution, Yamuna, Sewage, Spectroscopy, Chromatography

\section{Introduction}

River water quality has been shown to be deteriorating dramatically across the country as a result of growing urbanisation, industry, and poor infrastructure. Significant volumes of waste materials are discharged into the river by industrial communities all along the river's length. The Yamuna becomes a drain in its lower reaches, absorbing mostly agricultural, industrial, and household effluents (Ali et al., 2001). According to CPCB (2000), around 359 industrial units were discovered to be directly discharging and contaminating the river, including 22 units in Haryana, 42 units in Delhi, and 17 units in Uttar Pradesh. Paper, sugar, chemicals, leather, distilleries, medicines, and electricity are among these businesses. Yamunanagar, Sonepat, Panipat, Delhi, Agra, and Mathura are among the prominent and industrial cities along its banks. Pulp and paper, sugar, tanneries, and steel mills are among the businesses that discharge wastewater into the Yamuna river. Textiles, leather, chemicals, pharmaceuticals, rubber, glass, oil refineries, thermal power plants, and food are just a few examples (CPCB, 2006). The river Yamuna is quickly degrading into a sewer drain as a result of considerable human pressure. Domestic and industrial wastes, both treated and untreated, are discharged through small and major sewers in Delhi alone. The outflow of wastewaters through seven major drains, namely Najafgarh, Yamunapur, Sen Nursing Home, Barathpula, Maharanibag, Kalkaji, and Tuglakabad, is responsible for 95 per cent of Yamuna pollution in Delhi. The Yamuna River in Delhi is so dirty that it barely supports any sort of life beyond Okhla. Not only has the river been discovered to be depleted in organic matter and minerals, but it has also been shown to be depleted in pesticides and heavy metals (Aggrawal, 1993).

The Yamuna water quality at Okhla and Nizamudin bridges has been classified as the worst affected, according to the current state of water quality in India (2007) provided by CPCB. It was ranked seventh on the list of rivers with the greatest Biochemical Oxygen Demand (BOD), one of the most prominent markers of pollution, according to data on water quality of water bodies and groundwater sites. The Yamuna had a total biochemical oxygen demand of 93 $\mathrm{mg} / \mathrm{L}$, which was more than the allowed threshold of 3 $\mathrm{mg} / \mathrm{L}$. According to the CPCB study, the level of Dissolved Oxygen in the Yamuna was less than $4 \mathrm{mg} / \mathrm{L}$ throughout the year, and it was $0.0 \mathrm{mg} / \mathrm{L}$ in a few areas downstream of urban areas owing to the discharge of untreated and poorly treated effluent. At Paonta Sahib, Kalanaur, Sonepat, Palla, Nizammudin, Okhla, Mazawali, Mathura, Agra, Bateshwar, Etawah, Juhika, and Allahabad, the Yamuna's water quality has deteriorated, and the western Yamuna canal downstream of Yamuna Nagar at Damla is "grossly polluted due to municipal and industrial wastewater disposal."

\begin{tabular}{|c|c|c|}
\hline River Segments & Segment Area & $\begin{array}{l}\text { Approx. Segment } \\
\text { Length }\end{array}$ \\
\hline Himalayan Segment & $\begin{array}{l}\text { From origin to } \\
\text { Tajewala Barrage }\end{array}$ & $172 \mathrm{~km}$ \\
\hline Upper Segment & $\begin{array}{c}\text { Tajewala Barrage to Wa- } \\
\text { zirabad Barrage }\end{array}$ & $224 \mathrm{~km}$ \\
\hline Delhi Segment & $\begin{array}{l}\text { Wazirabad Barrage to } \\
\text { Okhla Barrage }\end{array}$ & $22 \mathrm{~km}$ \\
\hline Eutriphicated Segment & $\begin{array}{l}\text { Okhla Barrage to Chambal } \\
\text { Confluence }\end{array}$ & $490 \mathrm{~km}$ \\
\hline Diluted Segment & $\begin{array}{l}\text { Chambal Confluence to } \\
\text { Ganga Confluence }\end{array}$ & $468 \mathrm{~km}$ \\
\hline
\end{tabular}

Figure 1: Different segments of the river Yamuna

Determining Water Quality Status in the Yamuna River Nutrient, chemical, and biological analyses can be used to determine the quality of river water. A healthy river should have at least $5 \mathrm{mg} / \mathrm{L}$ of dissolved oxygen (essential for marine life survival) and around $3 \mathrm{mg} / \mathrm{L}$ of Biochemical Oxygen Demand. In addition, the number of pathogens (disease-causing bacteria) reflected by Faecal Coliforms counts should not exceed 500 per $100 \mathrm{~mL}$ of water. India is a country in South Asia. The properties of river water have been classified into five classes (http:// edugreen.teri.res.in/explore/maps/water.htm).

Class A: After disinfection with chlorine or bleaching powder, river water is safe to consume.

Class B: The river water in this grade is only suitable for bathing.

Class C: Only with proper treatment (screening to remove physical matter or particulates such as paper, plastic, etc.) is river water acceptable for drinking.

Class D: The river water in this classification is only appropriate for fish and animals.

Class E: River water is only suited for industrial cooling, irrigation, and other similar purposes. 
The Yamuna River is classified as a class E river. Since 1975, the Yamuna basin has experienced tremendous urbanisation, industrialization, and agricultural growth, all of which have had a direct or indirect impact on the Yamuna water quality. The Yamuna's water quality is further influenced by the river's six barrages. These barrages stopped the river from flowing and created a lotic (flowing) habitat.
The majority of the sludge is dumped upstream of the barrages, where it settles harmful elements that then migrate downstream with the abrupt release of water from the barrages, increasing river contamination.

Since 1977, the Central Pollution Control Board (CPCB) has been periodically monitoring and analysing the water quality of the Yamuna River.

\begin{tabular}{|c|c|c|c|c|}
\hline Site & Structure & State & Purpose & State of River \\
\hline Dak Patthar & Barrage & Uttranchal & Power Generation & Water diverted into canal \\
\hline Asan & Barrage & Uttranchal & Power Generation & Water diverted into canal \\
\hline Hathnikund & Barrage & Uttar Pradesh/Haryana & Irrigation and drinking water & $\begin{array}{l}\text { Water diverted into WYC and } \\
\text { EYC (No water flow down- } \\
\text { stream in dry season) }\end{array}$ \\
\hline Wazirabad & Barrage & Delhi & Drinking water & $\begin{array}{l}\text { Generally no water flow } \\
\text { downstream in dry season }\end{array}$ \\
\hline ITO bridge & Barrage & Delhi & Water supply to power plant & $\begin{array}{c}\text { Water available mainly from } \\
\text { drains }\end{array}$ \\
\hline Okhla & Barrage & Delhi/Uttar Pradesh & Water supply into Agra canal & $\begin{array}{l}\text { Generally no water flow } \\
\text { downstream in dry season }\end{array}$ \\
\hline
\end{tabular}

Figure 2: Diversion of Yamuna River Water, EYC ( East Yamuna Canal ), WYC ( West Yamuna Canal )

\section{Biological Oxygen Demand}

According to AK MISHRA'S report on the Yamuna river -

It quantifies the rate at which biological organisms in a water body use oxygen to break down organic materials damaged by sewage or industrial effluents. The high demand for BOD suggests that dissolved oxygen levels are decreasing, putting the river's marine life and biodiversity in jeopardy. The presence of high levels of organic contaminants and nitrate in the water body causes this. The BOD level in the Yamuna River from Yamunotri (source) to Palla (the point between Sonipat and Nizamuddin Bridge) in Delhi is normally between 1 and $3 \mathrm{mg} / \mathrm{L}$. The Yamuna is teeming with marine life up to Palla, but beyond there, wastewater drains have begun to overflow into the river. The BOD level varies from 3 to $51 \mathrm{mg} / \mathrm{L}$ downstream from Nizamuddin Bridge to Agra. In Mathura, Agra, Etawah, and Juhika, the BOD level was also found to be over the acceptable limits.

\section{Chemical Oxygen Demand}

COD levels beyond the allowed limit are a sign of organic and inorganic contaminants in the water.

From its source to Palla, the COD level in the Yamuna fluctuates from 1 to $50 \mathrm{mg} / \mathrm{L}$. Beyond the Palla Yamuna River, a huge volume of wastewater is received from various drains in Delhi and several downstream regions. From Nizamuddin Bridge to Juhika, the COD level began to rise and was determined to be over the allowed limits (ranges from 3 to $155 \mathrm{mg} / \mathrm{L}$ )- According to AK MISHRA'S report on the Yamuna river

\section{Dissolved Oxygen}

According to AK MISHRA'S report on the Yamuna river -
The amount of DO in the Yamuna was determined to be normal from its source to Palla, but it began to decline beyond that. After Wazirabad, the DO level drops dramatically, and the majority of the time, the DO level is observed to be nil in Delhi downstream places; this might be related to the Shahdara drain and Hindon River, which discharge wastewater at these places. Furthermore, the DO levels in Mathura, Agra, Etawah, and Juhika were found to be over the allowed limits. Across the years 1999 to 2005, ammonia levels in the whole Yamuna length ranged from zero to $44 \mathrm{mg} / \mathrm{L}$. The presence of Cadmium, Nickel, Iron, Zinc, and Chromium in the Yamuna River was discovered in a study of heavy metals at Palla and some of the impact places such as Nizamuddin Bridge, Agra Canal, Mathura downstream, and Agra downstream. In January 2001, in Agra downstream, the greatest concentration of chrome was recorded at $7.91 \mathrm{mg} / \mathrm{L}$, while the greatest concentrations of iron and zinc were discovered at $78.3 \mathrm{mg} / \mathrm{L}$ (Nizamuddin Bridge) and $1.37 \mathrm{mg} / \mathrm{L}$ (Palla) in July 2001 and June 2003, respectively. Pesticides are also commonly found in the Yamuna, in addition to heavy metals. Pesticides such as BHC (benzene hexachloride), Dieldrin, Aldrin, Endosulfan, and DDT have been discovered in Yamuna river water at various sites. In September 2005, the highest quantity of BHC (5517.79 g/L) was detected downstream of Agra. The highest concentrations of Aldrin (213.41 g/L, December 2001), Dieldrin (50.85 g/L, March 2005), and Endosulfan (4591.08 g/L, June 2002) were found downstream of Nizamuddin bridge and at Nizamuddin bridge, respectively [9].

Agriculture activities, which are abundant in the river catchment region as well as along the riverbank, appear to be the sources of pesticides in the Yamuna. Almost every year, mass fish deaths are reported from these sites, and right now, the presence of fish in the Yamuna River between Delhi and Agra is documented only on rare occasions. 


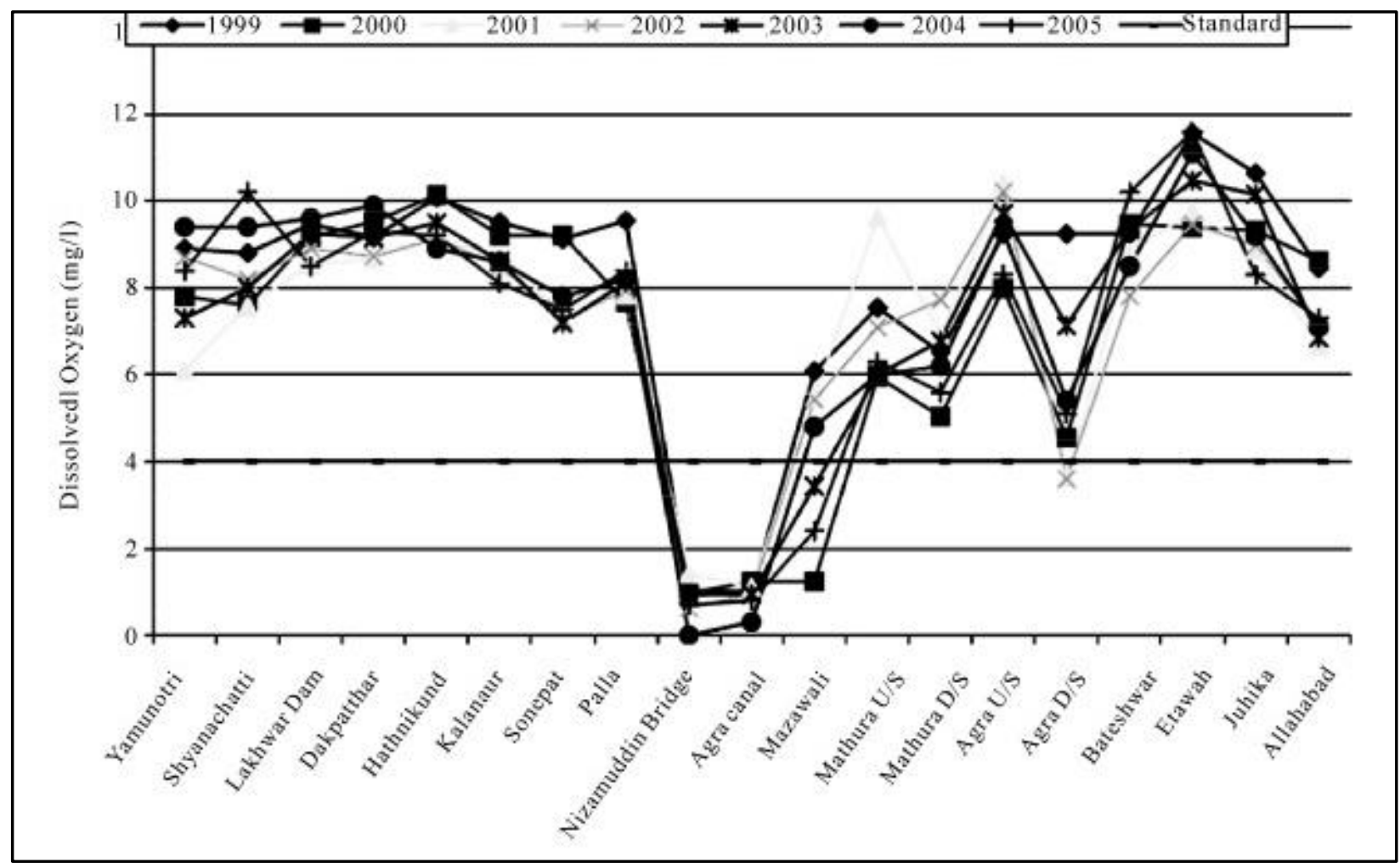

Figure 3: Average Biochemical Oxygen in Yamuna River

Modern Methods being used to determine water contamination levels

\section{Laboratory Oil Analysis}

Although laboratory oil analysis is still the most common method of monitoring water pollution, it isn't always the most effective strategy in terms of detecting early failures.

Oil samples are gathered and transported to an external laboratory for testing according to a predetermined test schedule. An occasional or unusual sample of fresh or used oil may also be sent to the lab for a specific reason, such as quality inspection of the incoming lubricant or when an issue is detected.

While this method is effective, the time it takes from the time the sample is obtained to the time the report is read might be a drawback, particularly if an aberrant condition is present. Karl Fischer titration, Fourier transform infrared (FTIR) spectroscopy, relative humidity sensors, and distillation are some of the technologies used in labs to detect moisture.

\section{Karl-Fischer Titration}

Because of its precision and constancy, Karl Fischer titration is the chosen test. Currently, ASTM D6304 is the approved approach. The results are either in parts per million (ppm) or as a percentage of the total volume of water. If a vaporizer is used to remove water from the sample, the test findings will be more precise for high-viscosity lubricants or formulations including sulphur and other chemicals. Toluene may dissolve water as well. Co-distillation is the name for this extra phase. The addition of some additives without vaporisation might cause 50-100 ppm errors. Of course, no laboratory test procedure is flawless, therefore there may be some variation in the findings. The variability of each test is normally reported by ASTM techniques in terms of repeatability and reproducibility. The Karl Fischer titration is no different. For moisture contents, more than 100-200 ppm, the findings of this approach are often more exact and reliable. Since 2016, ASTM 1744 (Standard Test for Determination of Water in Liquid Petroleum Products by Karl Fischer Reagent) has been decertified as an acceptable test method. While this test was simpler to administer, it was less accurate. Some laboratories, however, continue to use it.

\section{Relative Humidity Sensors}

For years, this technique has been used to determine the moisture content of materials in a variety of businesses. It was recently introduced to the lubrication industry as a means of monitoring pollutants in lubricating oils and greases. The ASTM D7546 standard backs it up (Standard Test Method for Determination of Moisture in New and InService Lubricating Oils and Additives by Relative Humidity Sensor). In general, an instrument warms a sample of test material and volatilizes the moisture, which is delivered by a dry-air system via a sensor block housing the relative humidity $(\mathrm{RH})$ sensor by a dry-air system. There are no reagents utilised. The values are either in parts per million (ppm) or as a percentage of water (micrograms). The method's repeatability and reproducibility have yet to be investigated.

\section{FTIR}

For lubricants, FTIR is a well-known and widely utilised resource. It can detect pollutants such as water, gasoline, and soot, as well as specific additives and oil deterioration, among other things. While there are various ASTM techniques linked to FTIR and petroleum products, ASTM E2412 and D7414 are the most relevant. Different factors in oil or grease samples may be measured using this rapid, lowcost test. One disadvantage is the lower detection limit of 
about 1,000 ppm. For specific infrared-light wavenumbers, the findings are presented in absorbance units. The moisture content may be expressed as a percentage or in parts per million (ppm) by the laboratory.

\section{Portable Field Equipments}

In a workshop or manufacturing facility, field lab analysis entails the use of portable instruments.

The technique is similar to that used in laboratories, but with a smaller gadget. Only a few drops of oil are usually necessary, and effects can be obtained in minutes. Aside from moisture content, other oil characteristics may be measured. The biggest disadvantage of this strategy is the cost. A popular field test instrument is a calcium hydride kit. This test employs a reagent and a solvent (kerosene or toluene) to create a reaction that produces gas from the sample's existing water. It basically determines the amount of emulsified and free water. Although low water quantities can be detected, this method appears to be more reliable at concentrations of 150-200 ppm. Another example of a typical field test is the crackling test. It evaluates the existence of emulsified and free water by placing two droplets of oil on the surface of a hot plate The minimal concentrations that may be identified are between 500 and 1,000 parts per million. It's crucial to pay attention to any little bubbles or crackling noises throughout this examination.

\section{Chromatography}

Chromatography is a technique for separating a mixture and obtaining both qualitative and quantitative information. Chromatographic divisions are performed using a constant free phase, known as the mobile phase, and a second sample-free phase, known as the stationary phase, which stays fixed. As the sample passes through the mobile phase, it separates its segments into stationary and mobile phases. Components with a distribution ratio that favours the stationary phase will take longer to finish the framework, whereas those that favour the mobile phase would take less time. It is feasible to separate solutes with identical distribution ratios given enough time and a stationary and mobile phase. Several analytical chemistry systems, highperformance liquid chromatography (HPLC), and gas chromatography are examples of chromatography (GC).

\section{Gas Chromatography}

In GC, the sample is infused into a flood of the versatile idle vaporous stage, which can be a gas or a fluid (often called carrier gas, for example, helium, argon or nitrogen). The sample is given by a pressed or capillary column, where it is divided into stationary and mobile phases based on its capacity to disperse. To have a good gas chromatography partition, you need to manage the temperature of the column. As a result, the column is housed in a thermostatic oven. In an anisothermal partition, the section is held at a constant temperature, with the choice being made by the solutes. The GC is usually combined with a detector such as a thermal conductivity detector (TCD), aflame ionisation detector (FID), an electron capture detector (ECD), and a mass spectrometer (MS). It is widely used to assess a wide range of samples in clinical, environmental, pharmaceutical, forensic, biochemical, food science, and petrochemical research facilities. GC is used to analyse a variety of organic pollutants in the air, water, and wastewater. For these approaches, proper pre-treatment, for example, and wellprepared staffs are essential.

\section{High-Performance Liquid Chromatography}

In HPLC, a sample (a liquid or solid sample dissolved in a suitable solvent) is aided by a mobile fluid phase and chromatographic segment. Interactions between the solution and the stationary phase control separation. In isocratic elution, the detachment employs a single mobile phase of constant composition.

It is usually difficult to find a single mobile phase composition that is acceptable for all solvents. As a result, the sole option is to use a gradient phase. To separate the reverse phase, the mobile phase's underlying composition is somewhat polar. As the separation progresses, the composition of the mobile phase becomes less polar. Different detectors for monitoring HPLC separation have been developed, similar to those for GC, and include spectroscopic detectors (e.g. UV/Vis absorption and fluorescence), electrochemical finders, and ongoing advances in mass spectrometry, leading to a growing interest in liquid chromatography-mass spectrometry (LC-MS). HPLC is often employed in pharmaceutical, environmental, criminal, clinical, and industrial investigations, both quantitative and qualitative.

These chromatographic methods are often used to analyse organic compounds. Chromatographic methods are very efficient and sensitive, particularly when paired with MS, but they need expensive, intricate equipment and skilled operators.

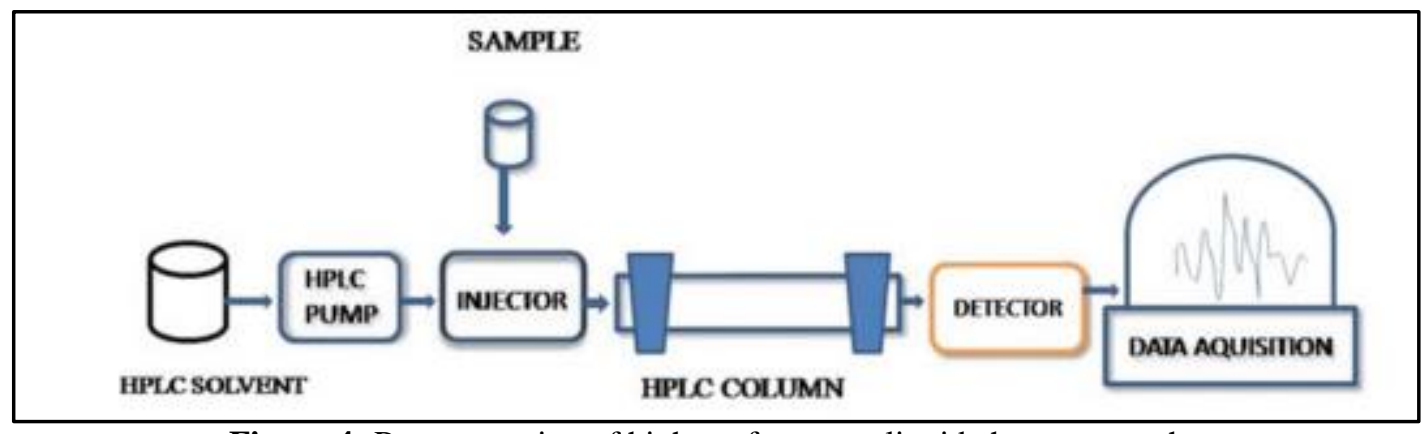

Figure 4: Representation of high-performance liquid chromatography 


\section{Atomic Spectroscopy}

Atomic spectroscopy encompasses all analytical techniques that make use of individual atoms' emission and absorption of electromagnetic radiation. It's an excellent method for determining the trace amounts of numerous elements in the periodic table. The element is recognised by the wavelength of the radiation (emitted or absorbed), and the strength of the transmitted (or absorbed) radiation is proportional to the amount of the element present.

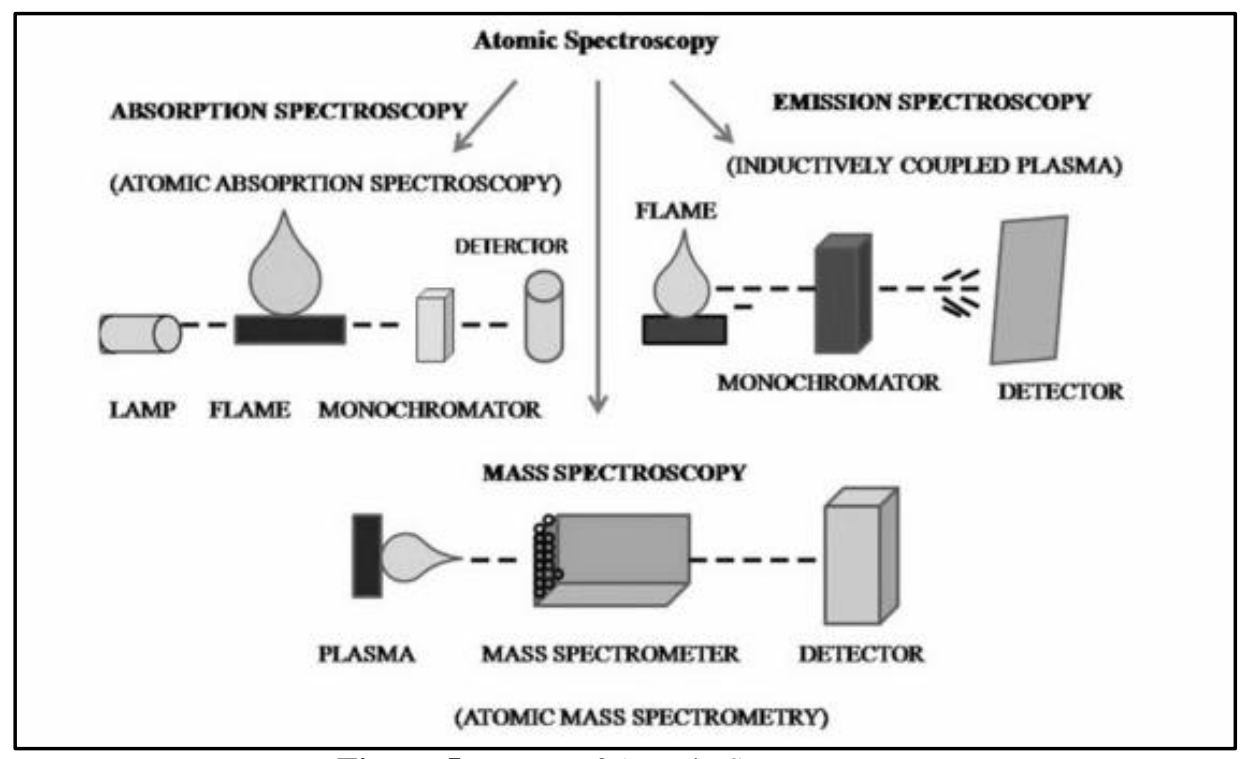

Figure 5: Types of Atomic Spectroscopy

\begin{abstract}
Atomic Absorption Spectroscopy
The discrete radiation absorbed by the absorption of a photon of energy by stimulating the atoms in the ground state to higher energy levels is estimated by atomic absorption spectroscopy. The absorbed radiation's radiant power is calculated using the Beer-Lambert equation and the ground-state atoms' absorption coefficient. Trace metals are commonly investigated by atomic absorption utilising either flame or electro-thermal atomization in a variety of test matrices.
\end{abstract}

The concentration of the analyte in the samples being examined is the primary determinant of the atomization approach. Because electro-thermal atomization has a higher sensitivity, the identification limits for most components are much lower than when utilising flame atomization. When the concentration of the analyte is much greater than the flame atomization detection limit, flame atomization is the preferred approach due to its greater accuracy. However, flame atomization is less prone to cause interference, has a higher sample throughput and needs less operator skill. Atomic absorption has high selectivity and may be used to evaluate more than 60 elements at concentrations as low as parts per million. When utilising flame atomization, the analysis time is quick, with a test throughput of 250-350 determinations per hour on a fully automated system.

However, unlike electrochemical equipment, this kind of analysis necessitates extensive sample preparation.

\section{Inductively Coupled Plasma (ICP)}

ICP is an atomic emission spectroscopic method that uses plasma to atomize the sample. Plasma has a large number of electrons and positive ions, which balance out and neutralise molecules. Plasmas are made up of highly energised and ionised gases formed by inert gases like argon. They aid in atom dissociation as well as excitation and ionisation, resulting in atomic and ionic emissions. ICP has lower detection limits than AAS, however, it requires a highly experienced operator. The main disadvantage of all atomic spectroscopy approaches is that they do not offer information on the element's oxidation state or speciation. This approach, like AAS, necessitates a highly competent operator and extensive example preparation.

\section{Fluorescence-Based Detection of Water Pollution}

Water pollution must be monitored in order to avoid health problems. While there are numerous methods for monitoring pollution levels in the water, regular management of pollution levels in water necessitates a more quick and fast methodology for analysing water quality. This approach may be used to identify a variety of contaminants in marine, surface, and groundwater, including organic matter, trace organics, and other contaminants. ANNs (artificial neural networks) and RVMs are two of the current methods for detecting water contaminants, which are based on classical water quality detection (relevance vector machines).

However, this method of determining water quality parameters has some drawbacks, including the fact that it takes a long time to complete, requires a variety of chemical reagents, is insensitive or insensitive, and generates a variety of waste. In contrast to traditional methods of water quality monitoring, spectra-based analysis detects pollutants without the need for separation or extraction, and it is very easy and quick, and it does not require any reagent for contaminant identification. Using the UV-visible spectrophotometry methodology, several researchers examine the water contamination or quality. The detection limit of certain organic materials, though based on this technology, is insufficient to meet the criteria.

For many years, fluorescence-based methods have been used to monitor water quality, and it is also the primary approach 
for routinely detecting organic matter dissolved in water, as well as pigments such as chlorophyll and algae. It identifies organic materials at a lower limit than the UV-Visible spectrum while also providing additional data. This approach uses less sample and detects the sample without processing; as a result, it does not harm the sample's structure; it has great selectivity, repeatability, and sensitivity.

Mechanism- The absorbance of contaminants under UV vision is used as a way of detecting water pollution. This approach identifies water pollutants by detecting the light produced by the contaminants after absorption at a shorter wavelength (lower wavelength) than the original wavelength. This approach detects just a small number of molecules, making it a very selective approach for detecting contaminants in water.

\section{Causations of pollution in the river Yamuna}

\section{Industrial Effluents}

The river water is unusually dark, resembling an industrial drain in Delhi, where the bulk of companies are located on its bank and discharge their untreated effluents into the river. Approximately nine months of the year, the Yamuna's water remains stagnant. In Delhi, Faridabad, Mathura, and Agra, there is an infinite number of industrial facilities emptying vast amounts of untreated water into the Yamuna. According to the Central Pollution Control Board (CPCB), around 359 industrial units release their effluents into the Yamuna River, either directly or indirectly. According to a CPCB assessment, roughly 42 industrial facilities in Delhi were directly contaminating the Yamuna.

\section{Waste Water from the Home}

Because of the high volume of wastewater discharge, the Yamuna is regarded as one of the most polluted rivers in the world, particularly in the Delhi area. According to a report conducted by the Central Pollution Control Board (CPCB), Delhi produces $23 \%$ of the total wastewater created by Class I cities (cities with more than 100,000 people). This is surprising, $47 \%$ of the trash created by 101 Class I cities and 122 Class II cities (population: 50,000-99,999) in the Ganga basin. When untreated home wastewater is thrown into the Yamuna, which contains ammonia, the concentration of ammonia in the river rises. When the ammonia content reaches $0.4 \mathrm{mg} / \mathrm{L}$ or more, the water becomes untreatable. Ammonia levels in the Yamuna River in Delhi have frequently exceeded $0.4 \mathrm{mg} / \mathrm{L}$, particularly during the summer. Due to the continual dumping of residential wastewater from Palla to Etawah, the river has become severely contaminated.

\section{Agriculture-related pollution}

Agriculture is also a major source of contamination in the Yamuna River, affecting river water quality directly or indirectly through ground and surface water runoff from agricultural land during monsoon and non-monsoon precipitation, as well as seepage of irrigation water containing artificial fertiliser residues, insecticides, and herbicides. Agriculture is prevalent in the catchment areas as well as along the Yamuna River's bank. During the nonmonsoon season, the majority of river streams diminish and their catchment regions are used for agriculture, resulting in pesticide residue being directly deposited in the river.

\section{Disposal of Solid Waste}

Solid wastes are undesired and abandoned goods in their solid condition, and they must be properly managed. One of the greatest issues in the Yamuna River is the dumping of solid waste and rubbish.

The concentration of suspended particles in the Yamuna is 1000-10,000 mg/L, according to the Yamuna Action Plan report, while the allowed concentration of suspended solids is $100 \mathrm{mg} / \mathrm{L}$.

The major reason for this is the city's high population density, as well as the dumping of untreated water and solid waste into the river. Solid waste, which consists primarily of human faeces and cow manure, is discharged untreated into the Yamuna River by several legal and unlicensed dairy colonies in Sonepat, Panipat, Delhi, Noida, Mathura, Agra, and Etawah, and is considered a major non-point source of pollution.

\section{Heavy Metals}

Heavy metals, in basic terms, are chemical elements with a high density that are poisonous in certain quantities. They can get into our bodies through food, water, or air. A process known as bioaccumulation can be used to justify their toxicity. Heavy metals tend to build up in the human body and are stored faster than they are broken down. Heavy metals are required in varying amounts by various living species.

Humans, for example, require $\mathrm{Fe}, \mathrm{Cu}, \mathrm{Mn}, \mathrm{Mg}, \mathrm{Mb}$, and $\mathrm{Zn}$. High quantities of such metals, on the other hand, are harmful to the organism. Heavy metals, on the other hand, such as mercury and lead, have no known advantages for humans, and their buildup causes serious health problems. Heavy metals, as previously stated, are hazardous to the human body in certain amounts. As a result, they have enormous ramifications for people. Our bodies require trace amounts of these heavy metals, but as their quantity rises, so does the toxicity associated with them. Humans are affected by heavy metals because our biological enzymes are disrupted. They have a proclivity for removing nutrients and binding their receptor sites. This has a significant impact on our nerves, digestion, hormones, and immunological function. They also cause a person's mental and cognitive health to deteriorate.

Numerous investigations have been undertaken to date to determine the presence of heavy metals in the Yamuna River. In a study of heavy metals in fish species (Sen et al., 2011), the characterisation of heavy metals in fish revealed that the concentrations of $\mathrm{Ca}, \mathrm{K}, \mathrm{Mg}, \mathrm{Na}$, and $\mathrm{P}$ were too high when compared to other metals and were not within the World Health Organization's maximum acceptable threshold (WHO). Pollution levels have dramatically grown as a result of environmental stress caused by people in the aquatic environment. Industrial discharge, organic material release into the water, household waste, and other factors have resulted in a decrease in oxygen levels and are a primary 
source of eutrophication. As a result, excessive algal growth causes depletion.

TERI also found moderate quantities of harmful metals in the water at many places in another study.

The samples were collected in and around the Yamuna River in Delhi and Haryana. The study also focused on the impact of heavy metals on river-grown veggies as well as the population that relies on river water. From 1999 to 2005, the Ministry of Environment and Forests' Central Pollution Control Board (CPCB) conducted a long-term study (Water Quality Status of Yamuna River, 2006) that focused on an in-depth analysis of the river Yamuna, its pollution sources, CPCB findings between 1999 and 2005, bacteriological contamination, the effect of micropollutants, and BOD load. The study also recommended that considerable actions be made to reduce pollution in the Yamuna. Another research (Sehgal et al., 2012) concentrated solely on heavy metal pollution in the Yamuna basin's Delhi sector.

From the Wazirabad barrage to the Okhla barrage, 13 locations were identified, and heavy metal concentrations in water and soil were measured. The following are some of the study's key findings:

The order of heavy metal concentrations in river water ranged from $\mathrm{Fe}>\mathrm{Cr}>\mathrm{Mn}>\mathrm{Zn}>\mathrm{Pb}>\mathrm{Cu}>\mathrm{Ni}>\mathrm{Hg}>\mathrm{As}>\mathrm{Cd}$.

The average heavy metal content in soil varied in the following order: $\mathrm{Fe}>\mathrm{Mn}>\mathrm{Zn}>\mathrm{Cr}>\mathrm{Pb}>\mathrm{Ni}>\mathrm{Hg}>\mathrm{Cu}>\mathrm{As}>\mathrm{Cd}$.

\section{Addressing Ammonia in the Yamuna}

Ammonia is a colourless gas that is used in the manufacturing of fertilisers, polymers, synthetic fibres, dyes, and other industrial chemicals. Ammonia is produced naturally in the environment as organic waste decomposes, but it can also enter ground and surface water sources through industrial effluents or sewage pollution. Fish are poisoned if the quantity of ammonia in the water exceeds 1 ppm. Long-term intake of water with ammonia levels of 1 ppm or more can harm internal organs in humans.

How does it make its way into the Yamuna?

The most likely cause is sewage from certain unsewered communities along this length of the river, as well as effluents from dye plants, distilleries, and other companies in Haryana's Panipat and Sonepat districts. The water for the city's supply is obtained from the Yamuna before it reaches the Wazirabad barrage. The Delhi Pollution Control Committee (DPCC) claims that discharge from Delhi's industry starts after this point. Drains 8 and 4, which deliver potable raw Yamuna water to Delhi from Haryana, are carrying significant concentrations of contaminants, according to a DJB official. In some parts of the Sonepat district, Drain 8 is also known for running alongside another drain transporting industrial trash and sewage. Sandbags are used in some regions to keep the two drains from mingling. Residents in the neighbourhood and specialists from the South Asia Network on Dams, Rivers, and People say that on days of severe rain, both drains overflow (SANDRP).
At this time, the DJB does not have any ammonia-treatment technology. Its only option is to cut output at three water treatment plants, Wazirabad, Chandrawal, and Okhla, which are all heavily impacted by the pollution. In addition, the board mixes raw water with a high ammonia concentration with fresh water from the Munak canal, which transports Yamuna water from Haryana to Delhi. When excessive quantities of ammonia are found, the quantity of chlorine applied to disinfect raw water is likewise increased. The DJB aims to treat ammonia levels up to $4 \mathrm{ppm}$ with the completion of a new unit of the Chandrawal water treatment plant by 2022 , which will be equipped with innovative technology and filters.

\section{Possible Recommendations}

\section{Fines and Regulations}

To prevent the rising pollution in the Yamuna River, it is now required to establish tough laws and regulations and assure their full application. Monitoring at the river's key contamination locations should begin promptly. Domestic waste and other polluting materials should not be dumped in rivers, and fines and imprisonment of 6 months to 1 year should be imposed based on a river's self-purifying abilities and waste assimilation capacities; effluent standards should be determined separately for each of the various polluters.

\section{Electric Cremations}

One of the causes of river water pollution is cremation in the Yamuna River and along its banks. Every day, between 100 and 150 cremations are carried out, the majority of them are carried out on wood pyres that do not totally consume the body. Thousands of more people who cannot afford cremation and whose bodies are just tossed into the Yamuna join the ashes of these traditional funerals. Moreover, each year, the corpses of thousands of dead animals, which are feared by Hindus, are thrown into the river.

Due to a lack of sufficient cremation facilities, there are a considerable number of partially unburnt bodies drifting down the Yamuna. The only way to solve these issues is to create electric cremation. Muslims and Christians bury their dead in cemeteries, but Hindus and Sikhs burn the bodies, and in the event of children's deaths, the bodies are thrown into rivers. It's not only good for the environment, but it's also cheap. Both the federal and state governments should step up their efforts to educate, inform, and persuade people to utilise electric cremation instead of wood for their final rites.

It is not only the most ecologically friendly but also the cheapest.

\section{Formation of Canals}

In the districts of Delhi, Agra, Mathura, and Etawah, the majority of rural and some urban areas do not have sewer systems. As a result, sewage and other household wastes run straight into the Yamuna River through open sewers. These wastes contaminate not just the river, but also the surface and groundwater resources. This should be prohibited at all costs, and a barrier should be built between the river and the cities/towns. Canals should be built parallel to the river to transport all of the town's household and sewage waste to a point 7 to 10 kilometres downstream of the town or city, 
where it will be treated and deposited into the river. This would not only assist to prevent pollution of the Yamuna, but it will also aid in the resolution of drinking water issues in Delhi, Mathura, and Agra.

\section{Construction of Public Restrooms}

In large cities like Delhi, Agra, Mathura, and Etawah, between 30 to 40 percent of the urban population lives in slums with no sanitary facilities. People in these places commonly practise open defecation and sewage discharge in the Yamuna river catchment region, resulting in the river's water quality worsening over time. Water polluted with faeces causes diarrhoea (the risk level can be reduced by $40 \%$ with good sanitation); malnutrition, anaemia or stunted development, blindness, schistosomiasis, and cholera, which are all frequent diseases in slum areas of Delhi, Mathura, and Agra. The greatest strategy for preventing future deterioration is the establishment of public sanitary facilities, particularly in slum communities located along both banks of the river.

\section{Sewage Treatment Plant Upgrades}

One of the biggest sources of water pollution in the Yamuna is the usage of antiquated, ineffective sewage infrastructure. All current sewage treatment plants must now be upgraded and their capacity increased. The majority of wastewater and trash is immediately discharged in river water or the ground in places without a sewage infrastructure, necessitating rapid action.

\section{Sewage Disposal in an Appropriate Manner}

Sewage effluent disposal is a major issue in practically every major metropolis. Because of their microbiological and chemical features, they cannot be easily discarded. They can only be released into the river once they have been thoroughly treated. However, the Yamuna receives around 1393 million gallons of untreated sewage from Delhi alone. Even partially treated sewage effluents are not entirely appropriate for release into rivers. To prevent water pollution in the Yamuna River, more sewerage treatment facilities should be built right away, and the discharge of untreated sewage should be prohibited.

\section{Sewerage System Improvements}

Due to the high amount of untreated or partially treated sewage water combined with river water, the state of sewerage systems, particularly in cities, towns, and blocks all along the Yamuna River's course, is exceedingly bad. Furthermore, many cities, small towns, and neighbourhoods lack sewage systems.

Improvements and construction of existing sewage systems are required to limit the danger of sewage water and material seepage into groundwater and rivers, particularly during rainy seasons.

\section{References}

[1] Water Quality Profile of Yamuna River , India Mahendra Pal Sharma

[2] Yamuna River Water Pollution-A Review - Pankaj. V. Sharma, Monika Bhadauriya

[3] A River about to Die: Yamuna - Anil Kumar Mishra
[4] Water Quality Status of River Yamuna in Delhi with reference to presence of heavy metals: a review - Divya Christopher, Simarpreet Kaur and Rachana Singh

[5] Modern Methods for Monitoring Water Contamination Alejandro Meza, Noria Corporation

[6] Analytical Methods of Water Pollutants Detection Gyanendra Tripathi, Jyoti Singh, Vishal Mishra

[7] High levels of ammonia in Yamuna water: The cause, effect and possible solution - Shivam Patel, edited by explained desk, The Indian Express 